10. Mazmanian, S.K., et al. 2003. Passage of heme-iron across the envelope of Staphylococcus aureus. Science. 299:906-909.

11. Bohach, G.A., and Foster, T.J. 1999. Staphylococcus aureus exotoxins. In Gram positive bacterial pathogens. V.A. Fischetti, R.P. Novick, J.J. Ferretti, and J.I. Rood, editors. American Society for Microbiology. Washington, D.C., USA. 367-378.

12. Fedtke, I., Gotz, F., and Peschel, A. 2004. Bacterial evasion of innate host defenses--the Stapbylococcus aureus lesson. Int. J. Med. Microbiol. 294:189-194.

13. de Haas, C.J., et al. 2004. Chemotaxis inhibitory protein of Staphylococcus aureus, a bacterial antiinflammatory agent. J. Exp. Med. 199:687-695.

14. Goodyear, C.S., and Silverman, G.J. 2003. Death by a B cell superantigen: in vivo $\mathrm{VH}$-targeted apoptotic supraclonal B cell deletion by a staphylococcal Toxin. J. Exp. Med. 197:1125-1139.

15. Novick, R.P. 2003. Mobile genetic elements and bacterial toxinoses: the superantigen-encoding pathogenicity islands of Staphylococcus aureus. Plasmid. 49:93-105.

16. Narita, S., et al. 2001. Phage conversion of Panton-Valentine leukocidin in Staphylococcus aureus: molecular analysis of a PVL-converting phage, phiSLT. Gene. 268:195-206.

17. Melles, D.C., et al. 2004. Natural population dynamics and expansion of pathogenic clones of Staphylococcus aureus. J. Clin. Invest. 114:1732-1740. doi:10.1172/JCI200423083.

18. Feil, E.J., et al. 2003. How clonal is Staphylococcus aureus? J. Bacteriol. 185:3307-3316.

19. Lina, G., et al. 1999. Involvement of Panton-Valentine leukocidin-producing Staphylococcus aureus in primary skin infections and pneumonia. Clin. Infect. Dis. 29:1128-1132.

20. Ito, T., et al. 2004. Novel type V staphylococcal cassette chromosome mec driven by a novel cassette chromosome recombinase, ccrC. Antimicrob. Agents Chemother. 48:2637-2651.

21. Ma, X.X., et al. 2002. Novel type of staphylococcal cassette chromosome mec identified in community-acquired methicillin-resistant Staphylococcus aureus strains. Antimicrob. Agents Chemother. 46:1147-1152.

22. Enright, M.C., et al. 2002. The evolutionary history of methicillin-resistant Staphylococcus aureus (MRSA). Proc. Natl. Acad. Sci. U. S. A. 99:7687-7692.

23. Gillet, Y., et al. 2002. Association between Staphylococcus aureus strains carrying gene for PantonValentine leukocidin and highly lethal necrotising pneumonia in young immunocompetent patients. Lancet. 359:753-759.

24. Fattom, A.I., Horwith, G., Fuller, S., Propst, M., and Naso, R. 2004. Development of StaphVAX, a polysaccharide conjugate vaccine against $S$. aureus infection: from the lab bench to phase III clinical trials. Vaccine. 17:880-887.

25. Hall, A.E., et al. 2003. Characterization of a protective monoclonal antibody recognizing Stapbylococcus aureus MSCRAMM protein clumping factor A. Infect. Immun. 71:6864-6870.

26. Vernachio, J., et al. 2003. Anti-clumping factor A immunoglobulin reduces the duration of methicillin-resistant Staphylococcus aureus bacteremia in an experimental model of infective endocarditis. Antimicrob. Agents Chemother. 47:3400-3406.

27. Weidenmaier, C., et al. 2004. Role of teichoic acids in Staphylococcus aureus nasal colonization, a major risk factor in nosocomial infections. Nat. Med. 10:243-245.

28. Roche, F.M., Meehan, M., and Foster, T.J. 2003. The Staphylococcus aureus surface protein SasG and its homologues promote bacterial adherence to human squamous nasal epithelial cells. Microbiology. 149:2759-2767.

29. O’Brien, L.M., Walsh, E.J., Massey, R.C., Peacock, S.J., and Foster, T.J. 2002. Staphylococcus aureus clumping factor $\mathrm{B}(\mathrm{ClfB})$ promotes adherence to human type I cytokeratin 10: implications for nasal colonization. Cell. Microbiol. 4:759-770.

\title{
Acid sensing in renal epithelial cells
}

\author{
Stephen L. Gluck \\ Division of Nephrology, UCSF, San Francisco, California, USA.
}

\begin{abstract}
The kidney adjusts net acid excretion to match production with exquisite precision, despite little or no change in the plasma bicarbonate concentration. The acid-sensing pathway that signals the kidney to increase acid secretion involves activation of the proto-oncogene c-Src. A new study in this issue shows that proline-rich tyrosine kinase 2 (Pyk2) is responsible for acid-induced activation of c-Src and is essential for acid sensing in renal epithelial cells (see the related article beginning on page 1782). The findings implicate a broader role for Pyk 2 in acid-base homeostasis in bone and other tissues beyond the kidney.
\end{abstract}

Although the principal product of metabolism in mammalian cells is the volatile acid carbon dioxide, humans on a typical Western diet produce about 70 millimoles of nonvolatile acid per day. Remarkably, varying metabolic acid production over a range of 0-150 millimoles is accompanied by a matching increase in net acid excretion by the kidney with a change of only $1 \mathrm{mM}$ in plasma bicarbonate concentration (1). The adaptive responses that enable the kidney to increase net acid excretion in response to

Nonstandard abbreviations used: FAK, focal adhesion kinase; NHE3, sodium/hydrogen exchanger 3; OKP, opossum kidney clone P; Pyk2, proline-rich tyrosine kinase 2 .

Conflict of interest: The author has declared that no conflict of interest exists.

Citation for this article: J. Clin. Invest. 114:1696-1699 (2004). doi:10.1172/JCI200423864. increased acid generation have been studied extensively in animal models of metabolic acidosis. In the proximal tubule, acidosis increases the activity of luminal and basolateral proteins involved in bicarbonate transport $(2,3)$, ammonia generation (4), and the reabsorption and metabolism of citrate (5). In the collecting duct, acidosis suppresses bicarbonate secretion (6) and stimulates recruitment of proton pumps to the luminal membrane of intercalated cells (7). Of the acid-base transporters in the proximal tubule, the luminal sodium/ hydrogen exchanger 3 (NHE3) has a prominent role, and the mechanism by which its activity increases during metabolic acidosis has been examined in some detail. Metabolic acidosis acutely increases the kinetic activity of NHE3 through direct $\mathrm{pH}$ effects and by phosphorylation (8), while chronic acidosis increases the number of NHE3 transporters (9).

\section{Acid-base transporter kinetics cannot account for precise $\mathrm{pH}$ sensing}

How does the kidney "know" to adjust net acid excretion with such precision with only minimal changes in plasma bicarbonate concentration? Available data in the physiology literature suggests that transporter kinetics alone cannot account for this degree of sensitivity. In the proximal tubule, a reduction in extracellular bicarbonate induces a fall in intracellular $\mathrm{pH}$, which directly activates the sodium/hydrogen exchanger through an intracellular $\mathrm{pH}$ regulatory site (10). This requires a change in intracellular $\mathrm{pH}$ of about 0.1 to achieve a $50 \%$ increase in the rate of transport or an approximately $5 \%$ change in the rate of transport in response to a change in extracellular bicarbonate concentration of $1 \mathrm{mM}$. Both the luminal vacuolar $\mathrm{H}^{+}$-ATPase and the basolateral sodium bicarbonate cotransporter in the proximal tubule are even less responsive to changes in intracellular $\mathrm{pH}(11-13)$. This suggests that a bicarbonate (or $\mathrm{pH}$ ) sensor that can amplify luminal proton secretion must be present. 


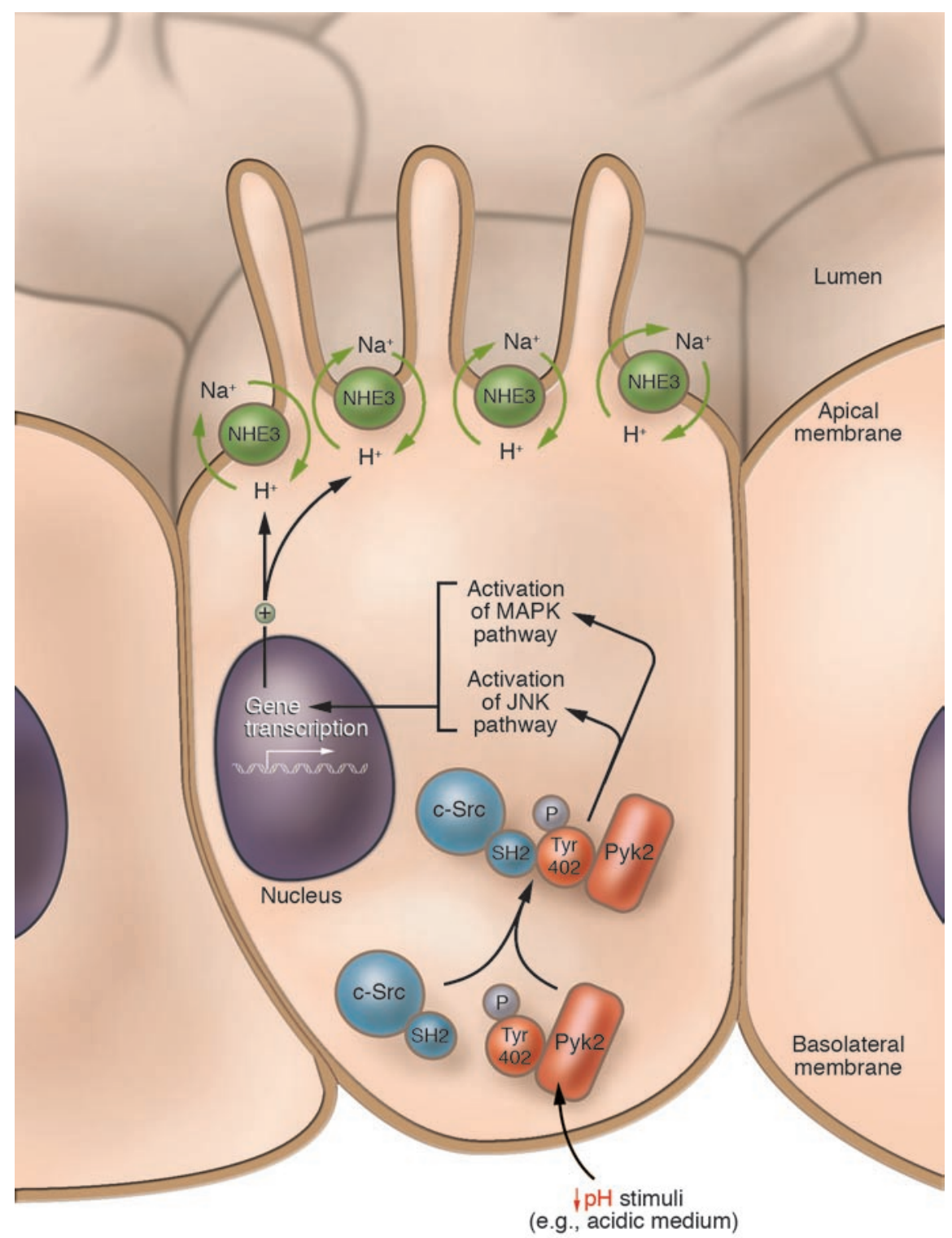

Figure 1

Acid-sensing pathway in renal proximal tubular cells. A drop in extracellular fluid pH induces a corresponding decrease in intracellular $\mathrm{pH}$ that induces activation of Pyk2, through an unidentified mechanism, by phosphorylation on tyrosine 402. Phosphorylated Pyk2 binds to the $\mathrm{SH} 2$ domain of $\mathrm{c}-\mathrm{Src}$, phosphorylating and activating it, producing subsequent activation of the MAPK and JNK signaling pathways and an increase in transcription of NHE3, the sodiumhydrogen exchanger of the proximal tubule brush border.

\section{Activation of NHE3 by cytosolic acidification requires c-Src phosphorylation}

In this issue of the JCI, Li, Sato, and colleagues (14) have attempted to identify the kidney's elusive $\mathrm{pH}$ sensor. These authors used cultured opossum kidney clone $\mathrm{P}$ (OKP) proximal tubule cells exposed to acid media as an in vitro model of the renal adaptation to acidosis. They found that a 24-hour exposure to acid increased NHE3
3-4 mM) were found to induce a detectable increase in phosphorylation of c-Src (18). Surprisingly, the phosphorylation of c-Src was greatest after only 90 seconds of cellular acidification, subsequently returning to a level slightly above baseline. This observation prompted the investigators to seek a protein that could sense small changes in cytosolic $\mathrm{pH}$ and induce c-Src phosphorylation within 90 seconds.

\section{Pyk2 is an activator of c-Src and candidate $\mathrm{pH}$ sensor}

In the present study (14), Li, Sato and colleagues make the case that the proline-rich tyrosine kinase 2 (Pyk2), a member of the focal adhesion kinase (FAK) family, acts as both a $\mathrm{pH}$ sensor and activator of $\mathrm{c}-\mathrm{Src}$. Pyk2, a 116-kDa cytoplasmic protein tyrosine kinase, is activated by phosphorylation on tyrosine residues in response to various stimuli, depending on the cell type, including growth factor receptors, chemokine receptors, G protein-coupled receptors, osmotic stress, cell depolarization, and others $(19,20)$ (Figure 1). For most of these stimuli, activation of Pyk 2 requires intracellular calcium release (19). In contrast to FAK, which is localized to adhesion plaques at the basal side of the cell, Pyk2 is located in the cytosol but can be recruited to plasma membrane, the perinuclear region, or the nucleus in response to different stimuli (20). Phosphorylation of tyrosine 402 on Pyk 2 induces the formation of a complex with the $\mathrm{SH} 2$ domain on c-Src (21), leading to activation of MAPK and JNK signaling pathways $(21,22)$.

$\mathrm{Li}$, Sato, et al. (14) show that Pyk2 is rapidly phosphorylated following exposure of renal epithelial cells to an acidic medium, with peak phosphorylation occurring at 30 seconds after exposure and followed by a persistent low level of increased phosphorylation. Expression of a catalytically inactive dominant-negative Pyk2 prevented the acid-induced activation of NHE3 but had no effect on glucocorticoid-stimulated NHE3 activation. Similarly, suppression of Pyk 2 protein by the transfection of cells with a small interfering RNA specific to the opossum mRNA inhibited acid-induced activation of NHE3 without affecting activation by glucocorticoids.

The authors showed that Pyk2 kinase activity and its binding to c-Src are essential for acid-induced c-Src activation. Acid incubation increased the amount of c-Src binding to Pyk2 (14). Further, in cells expressing the mutant Pyk2Y402F, which was gener- 
ated to eliminate the c-Src binding site, acid incubation produced no significant activation of NHE3. Finally, expression of a dominant-negative kinase-inactive Pyk2 prevented acid incubation from increasing the tyrosine kinase activity of c-Src.

Then how does the renal epithelial cell sense acid? The authors propose that Pyk2 itself is the sensor (14). They found that the kinase activity of Pyk2 in vitro is $\mathrm{pH}$ dependent, with a 3 -fold increase in kinase activity and a nearly 2-fold increase in autophosphorylation activity at $\mathrm{pH} 7.0$ compared with the normal intracellular $\mathrm{pH}, 7.2$. But the devil is in the details. The in vitro experiments were performed at an ATP concentration of $10 \mu \mathrm{M}$. The principal effect of $\mathrm{pH}$ was to shift the $K_{\mathrm{m}}$ for ATP from $129 \mu \mathrm{M}$ to 51 $\mu \mathrm{M}$, concentrations that are both far below the cytosolic ATP concentration. When kinase activity was measured at higher ATP concentrations, the decrease in $\mathrm{pH}$ had no effect. Li, Sato, et al. propose the interesting suggestion that the $\mathrm{pH}$ dependence of kinase activity may still be physiologically relevant, citing studies by Mandel and colleagues (23) showing that for the proximal tubule $\mathrm{Na}, \mathrm{K}$ ATPase, the apparent $K_{\mathrm{m}}$ for cellular ATP concentration in the intact tubule was much higher than the $K_{\mathrm{m}}$ for ATP concentration of the isolated enzyme. The studies by Mandel et al. are probably not comparable, however, since the $K_{\mathrm{m}}$ for ATP in the Na,K-ATPase is 10 -fold higher than that for Pyk2 and because the inhibitors used to alter cellular ATP levels (23) could have affected Na,KATPase activity indirectly.

Second, the authors showed that acid activation of Pyk 2 in vitro was inhibited by EGTA, which suggests calcium dependence, although their prior work showed no effect of acid incubation on cell calcium and no effect of the calcium buffer BAPTA (24), which prevents increases in cell calcium, on acid-induced immediate-early gene expression (16). Last, experiments in which Pyk2 was overexpressed showed no increase in basal NHE3 activity, as might be expected for a pathway sensitive to small changes in Pyk2 activity. So, although the studies provide compelling evidence that Pyk2 is crucial for the acid-sensing pathway, the elusive acid sensor remains a mystery.

\section{Importance of Pyk2 in acid-base homeostasis beyond the kidney}

Pyk2 is involved not only in luminal acid secretion, but also in basolateral bicarbonate exit in the proximal tubule (25). The findings of this study (14) have important implica- tions for acid sensing in other cells beyond the kidney. A surprising phenotype of the c-Src-knockout mouse is osteopetrosis (26), a disorder of inadequate osteoclast bone resorption. In other cell types, other Src family kinases such as Fyn and Yes probably compensate for c-Src deficiency (27). Osteoclasts respond to even subtle metabolic acidosis by secreting acid, which, rather than being excreted in urine, is buffered by alkaline bone salts (28). Recent studies show that Pyk2 binding to c-Src is essential for integrin-mediated osteoclast activation, although unlike kidney cells in the present study, osteoclast activation was not effected by expression of a kinase-inactive Pyk2 (29).

An important physiologic consequence of extracellular fluid acidification is release of endothelin from renal endothelium (30). Endothelin stimulates acid secretion in both the proximal tubule and collecting duct $(31,32)$. Pyk2 has a prominent role in the response of endothelial cells to a variety of mechanical, hormonal, and other stimuli (33). In cardiomyocytes Pyk2 is pivotal for integrin-mediated release of endothelin (34). It will be interesting to determine whether the acid-sensing pathway for endothelin release in endothelial cells is also Pyk2 dependent and what similarities this pathway shares with renal epithelial cells. It would be equally interesting to determine whether activation of endothelium through this pathway by mild or subclinical acidosis plays a role in the greatly increased risk of cardiovascular mortality found in patients with chronic kidney disease (35).

Address correspondence to: Stephen L. Gluck, Division of Nephrology, University of California San Francisco, 513 Parnassus Avenue, Box 0532, San Francisco, California 94143-0532, USA. Phone: (415) 476-2173; Fax: (415) 476-3381; E-mail: glucksl@medicine.ucsf.edu.

1. Kurtz, I., Maher, T., Hulter, H.N., Schambelan, M., and Sebastian, A. 1983. Effect of diet on plasma acid-base composition in normal humans. Kidney Int. 24:670-680.

2. Akiba, T., Rocco, V.K., and Warnock, D.G. 1987. Parallel adaptation of the rabbit renal cortical sodium/proton antiporter and sodium/bicarbonate cotransporter in metabolic acidosis and alkalosis. J. Clin. Invest. 80:308-315.

3. Preisig, P.A., and Alpern, R.J. 1988. Chronic metabolic acidosis causes an adaptation in the apical membrane $\mathrm{Na} / \mathrm{H}$ antiporter and basolateral membrane $\mathrm{Na}(\mathrm{HCO} 3) 3$ symporter in the rat proximal convoluted tubule. J. Clin. Invest. 82:1445-1453.

4. Nagami, G.T. 1989. Ammonia production and secretion by the proximal tubule. Am. J. Kidney Dis. 14:258-261.

5. Hamm, L.L., and Hering-Smith, K.S. 2002. Pathophysiology of hypocitraturic nephrolithiasis.
Endocrinol. Metab. Clin. North Am. 31:885-893, viii. 6. Garcia-Austt, J., Good, D.W., Burg, M.B., and Knepper, M.A. 1985. Deoxycorticosteronestimulated bicarbonate secretion in rabbit cortical collecting ducts: effects of luminal chloride removal and in vivo acid loading. Am. J. Physiol. 249:F205-F212.

7. Bastani, B., Purcell, H., Hemken, P., Trigg, D., and Gluck, S. 1991. Expression and distribution of renal vacuolar proton-translocating adenosine triphosphatase in response to chronic acid and alkali loads in the rat. J. Clin. Invest. 88:126-136.

8. Moe, O.W. 1999. Acute regulation of proximal tubule apical membrane $\mathrm{Na} / \mathrm{H}$ exchanger $\mathrm{NHE}-3$ : role of phosphorylation, protein trafficking, and regulatory factors. J. Am. Soc. Nephrol. 10:2412-2425.

9. Ambuhl, P.M., et al. 1996. Chronic metabolic acidosis increases NHE3 protein abundance in rat kidney. Am. J. Physiol. 271:F917-F925.

10. Aronson, P.S., Nee, J., and Suhm, M.A. 1982. Modifier role of internal $\mathrm{H}+$ in activating the $\mathrm{Na}+-\mathrm{H}^{+}$ exchanger in renal microvillus membrane vesicles. Nature. 299:161-163.

11. Nakhoul, N.L., Chen, L.K., and Boron, W.F. 1993. Effect of basolateral $\mathrm{CO} 2 / \mathrm{HCO} 3-$ on intracellular $\mathrm{pH}$ regulation in the rabbit $\mathrm{S} 3$ proximal tubule. J. Gen. Physiol. 102:1171-1205.

12. Soleimani, M., Lesoine, G.A., Bergman, J.A., and McKinney, T.D. 1991. A pH modifier site regulates activity of the $\mathrm{Na}+: \mathrm{HCO} 3$ - cotransporter in basolateral membranes of kidney proximal tubules. J. Clin. Invest. 88:1135-1140.

13. Nakhoul, N.L., Chen, L.K., and Boron, W.F. 1990. Intracellular $\mathrm{pH}$ regulation in rabbit $\mathrm{S} 3$ proximal tubule: basolateral Cl-HCO3 exchange and $\mathrm{Na}$ HCO 3 cotransport. Am. J. Physiol. 258:F371-F381.

14. Li, S., Sato, S., Yang, X., Preisig, P.A., and Alpern, R.J. 2004. Pyk2 activation is integral to acid stimulation of sodium/hydrogen exchanger 3. J. Clin. Invest. 114:1782-1789. doi:10.1172/JCI200418046.

15. Horie, S., Moe, O., Tejedor, A., and Alpern, R.J. 1990. Preincubation in acid medium increases $\mathrm{Na} / \mathrm{H}$ antiporter activity in cultured renal proximal tubule cells. Proc. Natl. Acad. Sci. U. S. A. 87:4742-4745.

16. Yamaji, Y., Moe, O.W., Miller, R.T., and Alpern, R.J. 1994. Acid activation of immediate early genes in renal epithelial cells. J. Clin. Invest. 94:1297-1303.

17. Yamaji, Y., et al. 1995. Overexpression of csk inhibits acid-induced activation of NHE-3. Proc. Natl. Acad. Sci. U. S. A. 92:6274-6278.

18. Yamaji, Y., Tsuganezawa, H., Moe, O.W., and Alpern, R.J. 1997. Intracellular acidosis activates c-Src. Am. J. Physiol. 272:C886-C893.

19. Avraham, H., Park, S.Y., Schinkmann, K., and Avraham, S. 2000. RAFTK/Pyk2-mediated cellular signalling. Cell. Signal. 12:123-133.

20. Schlaepfer, D.D., and Hunter, T. 1998. Integrin signalling and tyrosine phosphorylation: just the FAKs? Trends Cell Biol. 8:151-157.

21. Dikic, I., Tokiwa, G., Lev, S., Courtneidge, S.A., and Schlessinger, J. 1996. A role for Pyk2 and Src in linking G-protein-coupled receptors with MAP kinase activation. Nature. 383:547-550.

22. Tokiwa, G., Dikic, I., Lev, S., and Schlessinger, J. 1996. Activation of Pyk2 by stress signals and coupling with JNK signaling pathway. Science. 273:792-794

23. Soltoff, S.P., and Mandel, L.J. 1984. Active ion transport in the renal proximal tubule, III: the ATP dependence of the Na pump. J. Gen. Physiol. 84:643-662.

24. Tsien, R.Y. 1980. New calcium indicators and buffers with high selectivity against magnesium and protons: design, synthesis, and properties of prototype structures. Biochemistry. 19:2396-2404.

25. Espiritu, D.J., Bernardo, A.A., Robey, R.B., and Arruda, J.A. 2002. A central role for Pyk2-Src interaction in coupling diverse stimuli to increased epithelial NBC activity. Am. J. Physiol. Renal Physiol. 
283:F663-F670.

26. Soriano, P., Montgomery, C., Geske, R., and Bradley, A. 1991. Targeted disruption of the c-Src proto-oncogene leads to osteopetrosis in mice. Cell. 64:693-702

27. Martin, G.S. 2001. The hunting of the Src. Nat. Rev Mol. Cell Biol. 2:467-475.

28. Frassetto, L., Morris, R.C., Jr., Sellmeyer, D.E., Todd, K., and Sebastian, A. 2001. Diet, evolution and aging-the pathophysiologic effects of the postagricultural inversion of the potassium-to-sodium and base-to-chloride ratios in the human diet. Eur. J. Nutr. 40:200-213.
29. Miyazaki, T., et al. 2004. Src kinase activity is essential for osteoclast function. J. Biol. Chem. 279:17660-17666.

30. Wesson, D.E., Simoni, J., and Green, D.F. 1998. Reduced extracellular $\mathrm{pH}$ increases endothelin-1 secretion by human renal microvascular endothelial cells. J. Clin. Invest. 101:578-583.

31. Khanna, A., Simoni, J., Hacker, C., Duran, M.J., and Wesson, D.E. 2004. Increased endothelin activity mediates augmented distal nephron acidification induced by dietary protein. J. Am. Soc. Nephrol. 15:2266-2275

32. Laghmani, K., Preisig, P.A., and Alpern, R.J. 2002.
The role of endothelin in proximal tubule proton secretion and the adaptation to a chronic metabolic acidosis. J. Nephrol. 15(Suppl. 5):S75-S87.

33. Orr, A.W., and Murphy-Ullrich, J.E. 2004. Regulation of endothelial cell function BY FAK and PYK2. Front. Biosci. 9:1254-1266.

34. Kodama, H., et al. 2003. Selective involvement of $\mathrm{p} 130 \mathrm{Cas} / \mathrm{Crk} / \mathrm{Pyk} 2 / \mathrm{c}-\mathrm{Src}$ in endothelin-1-induced JNK activation. Hypertension. 41:1372-1379.

35. Go, A.S., Chertow, G.M., Fan, D., McCulloch, C.E., and Hsu, C.Y. 2004. Chronic kidney disease and the risks of death, cardiovascular events, and hospitalization. N. Engl. J. Med. 351:1296-1305.

\title{
TB, or not TB: that is the question - does TLR signaling hold the answer?
}

\author{
Terence M. Doherty ${ }^{1}$ and Moshe Arditi²
}

\author{
${ }^{1}$ Atherosclerosis Research Center, Division of Cardiology, and \\ 2Department of Pediatric Infectious Diseases and Immunology, Cedars-Sinai Medical Center, Los Angeles, California, USA
}

\begin{abstract}
Innate immunity critically depends on signaling by Toll-like receptors (TLRs) that rely heavily on an intracellular adapter protein called myeloid differentiation factor 88 (MyD88). Adaptive immune defenses are generally thought to be orchestrated by innate immune responses and so should require intact TLR-MyD88 signaling pathways. But a surprising new study in MyD88-null mice infected with Mycobacterium tuberculosis challenges this view and instead suggests that MyD88 may not be absolutely required for a normal adaptive immune response (see the related article beginning on page 1790).
\end{abstract}

Every second of every day, Mycobacterium tuberculosis (MTB) infects another human being somewhere in the world (1), yet the global incidence of around 8 million cases of active tuberculosis (TB) per year is only a tiny fraction of the estimated 2 billion people infected. Only around 1 in 10 of those infected will ever develop active disease, which raises a question: why do some individuals develop disease, while others do not? The answer is not trivial: in 2002, TB caused an estimated 2 million deaths, mostly in underdeveloped countries, and over the last century, TB has killed an estimated 100 million people $(1,2)$. A solid mechanistic understanding of how MTB infection proceeds and how host defenses are marshaled against it (both successfully and unsuccessfully) has proven elusive and remains an important goal.

Nonstandard abbreviations used: IRF, IFN-regulated factor; MTB, Mycobacterium tuberculosis; MyD88, myeloid differentiation factor 88 ; NOD, nucleotide-binding oligomerization domain; TB, tuberculosis; TIR, Toll/IL-1 receptor resistance; TLR, Toll-like receptor; TRAM, TRIF-related adapter molecule; TRIF, TIR domain-containing adapter inducing IFN- $\beta$.

Conflict of interest: The authors have declared that no conflict of interest exists.

Citation for this article: J. Clin. Invest. 114:1699-1703 (2004). doi:10.1172/JCI200423867.
In this issue of the JCI, Fremond and coworkers report data that expand our understanding of the host defense against M. tuberculosis infection yet raises provocative new questions that will be sure to spark controversy (3). They used mice with a genetic deficiency in myeloid differentiation factor 88 (MyD88), a critical adapter molecule common to signaling by most Toll-like receptors (TLRs). MyD88 $/$ - mice were subject to infectious challenge with MTB and died within 4 weeks, showing evidence of massive, uncontrolled pulmonary growth of the infectious organism. Adaptive immune responses appeared to be unaffected, but iNOS activation and expression of the defensive cytokines TNF- $\alpha$, IL- 6 , and IL-12 p40 were strongly reduced in MyD88-/- macrophages and DCs. Analyses of infected lung tissues revealed massive infiltration of mononuclear cells and neutrophils in infected MyD88-null mice, as might be expected, but flow cytometric studies showed no differences in $\mathrm{CD}^{+}$and $\mathrm{CD}^{+} \mathrm{T}$ cell recruitment to lungs between infected MyD88-null and wild-type mice. These results are consistent with a normal adaptive immune response and a robust inflammatory response with increased neutrophil and macrophage recruitment in MyD88-null mice yet markedly blunted defense by innate mechanisms that eventually proved lethal. Perhaps the most intriguing finding was that vaccination of MyD88-null mice with Mycobacterium bovis BCG induced appropriate activation of $\mathrm{T}$ cells and induction of a Th1 response to mycobacterial antigens, but this only forestalled death, despite the fact that induction of cytokines (IL- $1 \beta$, IFN- $\gamma$, TNF- $\alpha$, MIP- $1 \alpha$, and MCP-1) in the lungs did not differ between MyD88-null mice and wild-type controls. The authors concluded that MyD88-dependent signaling is not significantly involved in $\mathrm{T}$ cell activation but that in the absence of MyD88, $T$ cell-mediated immunity can afford only partial protection from infection. At face value, this work would appear to offer a plausible answer to the question posed - TB, or not TB? - namely, that innate immunity in general and TLR signaling through MyD88 are essential for the host to take arms against the sea of troubles that MTB infection brings. But how does this answer square with what we know about the interaction between innate and adaptive immunity?

\section{Signaling by Toll-like receptors and MyD88 in innate immunity}

Defense against invading pathogens comes in 2 major forms. Innate immunity rapidly mounts a multipronged defense that is relatively nonspecific and relies heavily on inflammatory molecules directly or indirectly toxic to pathogens. Adaptive 